\title{
Long-term maintenance and public exhibition of deep-sea Hydrothermal fauna: the AbyssBox project
}

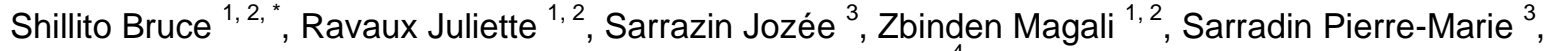 \\ Barthelemy Dominique ${ }^{4}$
}

${ }^{1}$ Sorbonne Universités, UPMC Univ Paris 06, UMR CNRS 7208, Adaptations aux Milieux Extrêmes, F75005, Paris, France

${ }^{2}$ MNHN, UMR CNRS 7208, Biologie des ORganismes et Ecosystèmes Aquatiques (BOREA), F-75005, Paris, France

${ }^{3}$ Ifremer, Centre de Bretagne, REM/EEP, Laboratoire Environnement Profond, Institut Carnot

EDROME, F-29280 Plouzané, France

${ }^{4}$ Océanopolis, Port de Plaisance du Moulin Blanc BP91039, 29210 Brest Cedex 1, France

* Corresponding author : Bruce Shillito, Tel.: +33 01442735 02. ;

email address : Bruce.Shillito@snv.jussieu.fr

\begin{abstract}
:
The AbyssBox project aims to provide the first permanent public exhibition of live deep-sea hydrothermal fauna maintained at in situ pressure. AbyssBox is a pressurized aquarium designed to function permanently. Here we present details of the project after the public exhibition functioned for more than three years at Océanopolis aquarium in Brest. France. We also describe the AbyssBox pressure aquarium, and provide data and observations on vent shrimp (Mirocaris fortunata) and crabs (Segonzacia mesatlantica) that were sampled from $1700 \mathrm{~m}$ depth at the Lucky Strike vent field (MidAtlantic Ridge) during different cruises. While mortalities exceeded $50 \%$ during the first days following sampling, the remaining animals appeared to acclimate fairly well. Some crabs have now been kept for more than 2 years, and some shrimp have spent more than 3 years in captivity. Primarily designed for a public exhibition, the AbyssBox is already used for scientific purposes, since it provides one of the most effective tools for long-term rearing of deep-sea fauna. AbyssBox is a first step towards maintaining a variety of deep-sea fauna year-round at in situ pressure, which will serve both scientific and public interests.
\end{abstract}

Keywords : AbyssBox, Aquaria, Aquariology, Deep waters, Hydrostatic Pressure, Hydrothermal vents, Public exhibition, Scientific experiments 


\section{Introduction}

The deep sea is by far the largest environment on the planet, with at least $50 \%$ of the biosphere lying below $1000 \mathrm{~m}$ depth in the ocean (Fang et al., 2010). While the last 40 years have substantially increased our knowledge of the ecological and biological diversity of the deep sea, much is yet unknown regarding the ecology and biology of the deep-sea biota because this remote environment is difficult and expensive to access and sample. In the meantime, the growing impact of human activities on the deep sea (Glover and Smith, 2003; Ramirez-Llodra et al., 2011), with the associated risk of extinguishing species (Devine et al., 2006), has become evident. Improving our knowledge of deep-sea habitats is therefore an urgent matter in order to allow sensible management of these areas in the future (Mengerink et al., 2014).

A valuable approach to understanding ecosystem functioning is the experimentation on live animals, either in the field or the laboratory (Spicer, 2014). However, because deepsea organisms usually have low tolerance to sampling and prolonged exposure at atmospheric pressure (see Pradillon, 2011), such laboratory studies require the use of specific mesocosms that restore pressure and temperature conditions that prevail in natural deep-sea habitats. Provided such devices are used, valuable knowledge can be gained on behavioural, physiological, or molecular responses of deep-sea biota with respect to acute environmental perturbations (Shillito et al., 2014). Most in vivo studies have, until now, involved short-term experiments on deep fauna (i.e., a few hours, see for example Airries and Childress, 1994;

Girguis and Lee, 2006; Ravaux et al., 2013). Longer term experimental approaches at in situ pressure for several days or weeks have only rarely been attempted (Yayanos, 1978; Holden, 1998; Koyama et al., 2002). Long maintenance times, at the scale of months to years, would undoubtedly allow questions to be addressed on lifespan or reproduction cycles and species 
interactions, which are often poorly characterized. It would also complement in situ longterm monitoring of deep-sea habitats, a highly valuable approach (Juniper et al., 2007, 2013) that has recently begun, with pioneering projects such as the EMSO-Açores Momar MoMAR program (; Sarrazin et al., 2007, 2014; Cannat et al., 2011) and the Neptune Canada observatory network (Juniper et al., 2013; Cuvelier et al., 2014).

To our knowledge, few attempts have succeeded in maintaining deep-sea fauna in the laboratory year-round, and most of them were achieved at atmospheric pressure (Miyake et al., 2007; Hamasaki et al., 2010; Tsuruwaka and Shimada, 2011; Smith et al., 2013). One of the successful attempts occurred at the Enoshima public aquarium (Miyake et al., 2007), therefore matching scientific interests with a growing demand of the public to learn more about the deep sea by promoting access to its remote fauna.

The AbyssBox project aims to provide the first permanent public exhibition of live deep-sea hydrothermal fauna maintained at in situ pressure. AbyssBox is a pressurized aquarium designed to function permanently. While primarily designed for a public exhibition, AbyssBox is also available to the scientific community, providing one of the most useful tools for long-term rearing of deep-sea fauna. Here we present details of the project, after the exhibition functioned for more than three years at Océanopolis aquarium in Brest, France. We first describe the AbyssBox pressure aquarium and also discuss its scientific potential. In addition, we provide data and observations on vent shrimp Mirocaris fortunata (Martin and Christiansen, 1995) and crabs Segonzacia mesatlantica, (Williams, 1988) which were sampled for the exhibition at $1700 \mathrm{~m}$ depth in the Lucky Strike vent field on the Mid-Atlantic Ridge (MAR) during different oceanographic cruises.. 2. Material and methods 


\subsection{The exhibition project}

The project was initiated at the end of 2009 following a deep-sea conference in Japan, with a 3-year period of preparation planned before public inauguration in April 2012. The general aim of the project was to draw the public's attention towards the deep ocean, by achieving the first permanent exhibition of live deep-sea hydrothermal animals maintained at habitat pressure. Because AbyssBox is a prototype, directly inspired by existing scientific instruments (Ravaux et al., 2013; Shillito et al., 2014), and because access to the deep sea is still mainly reserved to scientists, it was decided that the marine exhibition would not only display live fauna, but also occupy a dedicated section in Océanopolis, with scientific and technical information. Therefore, general knowledge of deep-sea ecosystems, with a particular focus on chemosynthetic habitats (vents, seeps, animal carcasses), was disseminated using posters and videos. The technical aspects of deep-sea research and exploration were also highlighted, firstly by deliberately showing all external parts of the AbyssBoxes to the public, as opposed to just showing the captive animals behind the main viewport, and secondly by presenting and explaining the technical function of specific parts of the system. The difficulties and technical aspects of deep-sea diving and sampling were to be illustrated by videos of scientific cruises, an interactive display of various facets of hydrostatic pressure, and by an original video game simulating deep-sea sampling with a remotely operated vehicle. Finally, the general layout of the exhibition was that of a scientific laboratory on board an oceanographic ship. 


\subsection{The AbyssBox aquarium}

The AbyssBox aquarium is a prototype inspired by the IPOCAMP aquarium (Shillito et al., 2014). It consists of a large pressurized vessel (about 16.5 1), which may function at pressures up to $20 \mathrm{MPa}$ (equivalent to approximately $2000 \mathrm{~m}$ depth), and at temperatures ranging from 2 to $40^{\circ} \mathrm{C}$. AbyssBox is a flow-through system which circulates seawater, with flow rates that may reach $10 \mathrm{l} / \mathrm{hr}$, and it is designed to maintain deep-sea fauna alive, thereby enabling in vivo experimentation. A large conical viewport allows observation of the pressurized vessel content while in function. Schematically, the system is divided into five parts:

1 - A seawater inlet line delivers filtered (25 $\square \mathrm{m}$ mesh) water to the system, at atmospheric pressure. A high-pressure pump pressurizes the water, which is further circulated through a heat-exchange device prior to its entry in the vessel, at its highest point.

2 - A stainless steel 16.51 vessel serves as an experimental chamber of $32 \mathrm{~cm}$ diameter and $20.5 \mathrm{~cm}$ depth. The vessel is made of $316 \mathrm{Ti}$ stainless steel, and is composed of 2 main parts (rear and front) assembled by 16 screws, and sealed together by an O-ring. Its Maximum Working Pressure (MWP) is $25 \mathrm{MPa}$ at $100^{\circ} \mathrm{C}$, and its test pressure is $38 \mathrm{MPa}$ at room temperature. It is equipped with an O-ring closing lid at the rear, and with temperatureregulating outer envelopes. The closing lid (Figures 1,2A) is equipped with a conical viewport providing a $35 \mathrm{~mm}$ optical diameter. Four conical viewports are placed by pairs at a $45^{\circ}$ "down-looking" angle on the side of the front part. Each of them provides a $1 \mathrm{~cm}$ optical diameter for illumination of the chamber by means of optical-fibre light-guides. At the front (facing the observer), a conical-shaped viewport of $15 \mathrm{~cm}$ outside diameter, $30 \mathrm{~cm}$ inside diameter, and $8 \mathrm{~cm}$ thickness, provides a view into the aquarium for the public.

3 - A seawater outlet line is connected to the aquarium at its lowest point, where the water is filtered (1 $\square \mathrm{m}$ mesh), so that animal wastes are collected before the water reaches a 
manually-operated back-pressure valve. This valve allows the setting and control of the working pressure. The circulating water returns to atmospheric pressure once past the backpressure valve.

4 - An isobaric feeding line of $1 \mathrm{~cm}$ internal diameter is located above the pressure vessel. This line can be depressurized to allow the introduction of food at atmospheric pressure, and re-pressurized to allow the food to sink inside the pressure vessel without its decompression. 5 -There are temperature-regulation units, the main one being designed to circulate cooling/heating fluid around the experimental vessel and the inlet line, and thereby setting the background temperature $\left(10^{\circ} \mathrm{C}\right) .2 \mathrm{Pt} 100$-type probes measure the temperature of the seawater when it enters the vessel (upstream), and when it leaves it (downstream). A smaller regulator circulates cooling/heating fluid $\left(27^{\circ} \mathrm{C}\right.$ temperature) through a ring-shaped tube $(6$ mm internal diameter) which is situated inside the aquarium, in order to create a "hotspot" for the animals, with respect to the background temperature.

The weight of the aquarium is approximately $640 \mathrm{~kg}$. It rests on a stainless steel frame, in such a way that the main viewport is positioned at a height of $1.2 \mathrm{~m}$, according to public exhibition standards (see Figure $2 \mathrm{~B}$ ). The pressure prevailing in the aquarium and the corresponding constraint on the main viewport (in tons) are provided to the observer by LCD displays facing the public. The temperature values for in- and out-coming water are also displayed. Inside the aquarium, a horizontal PVC grid is positioned at the bottom of the tank, thus providing space for animals to either walk or rest, and also preventing the latter from being drawn in the water outlet. Another PVC grid is positioned vertically at the rear of the aquarium (with respect to the observer) in order to provide further space for crabs and shrimp. Finally, in a central and horizontal position, facing the viewport, the ring-shaped heatexchanger is embedded in a PVC foam material (Figure 2C, D). Two AbyssBoxes were built to be part of the exhibition at Océanopolis. 


\subsection{Sampling and shipping of vent fauna}

Two species were sampled for the AbyssBox project: the hydrothermal vent crab Segonzacia mesatlantica (Williams, 1988) and the vent shrimp Mirocaris fortunata (Martin and Christiansen, 1995) (Figure 3). Sampling of animals took place during three cruises, in July 2011, 2012, and 2013, respectively (Momarsat, 2011, 2012; Biobaz, 2013), on board the oceanographic vessels "Pourquoi Pas?" (Momarsat, 2011; Biobaz 2013) and "Thalassa" (Momarsat, 2012) using the Remotely Operated Vehicle (ROV) Victor6000. Two methods were used to collect the animals: suction sampling (crabs and shrimp), or deployment of baited traps (crabs only). The sampling area was the Lucky Strike hydrothermal vent field at $\sim 1700 \mathrm{~m}$ depth along the MAR. The captive animals were retrieved from the bottom to the surface following the speed of ascent of the ROV (about $30 \mathrm{~m} / \mathrm{min}$ ), or that of the shuttle device (about $60 \mathrm{~m} / \mathrm{min}$ ) in the case of baited traps that were stored in the shuttle.

Immediately after sampling, the shrimp were stored in the cold room at a temperature of $5-9^{\circ} \mathrm{C}$, in tanks of approximately 5 to 101 of seawater, in groups of about 50 individuals. Crabs were stored at in situ pressure $(18 \mathrm{MPa})$ and $7^{\circ} \mathrm{C}$, using the IPOCAMP flow-through pressure vessel (a 191 pressure aquarium described in Shillito et al. 2001, 2014) during the Momarsat 2011 cruise. During the Momarsat (2012) and Biobaz (2013) cruises, they were kept at atmospheric pressure in the cold room at a temperature of $5-9{ }^{\circ} \mathrm{C}$, in tanks of approximately 5 to 101 of aerated seawater, in groups of a few individuals $(<5)$. The size of the animals ranged from 2 to $3 \mathrm{~cm}$ total length for shrimp, and 2 to $5 \mathrm{~cm}$ cephalothorax width for crabs (Figure 3).

While water in the atmospheric pressure tanks was renewed every day,water inside the IPOCAMP pressure vessel (for crab maintenance) was renewed permanently at a rate of 10 1/hr. Animals were never fed during maintenance on board the ships. Mortality counts 
were done on a daily basis, and all dead animals were removed from the maintenance tanks. When pressurized maintenance was available (2011 cruise, for crabs), the pressure vessel was opened, and the animals were checked upon each new arrival of samples.

At the end of the cruises, the ships returned to Horta (Faial, Azores, in 2011 and 2013) or Ponta Delgada (Sao Miguel, Azores, in 2012). For the 2011 cruise, the ship was scheduled to return to Brest a week later, where the Océanopolis aquarium is located. Therefore, all the animals were kept on board, in the same condition as during the cruise, while staff from Océanopolis boarded the ship to insure adequate maintenance during transit from Faial to Brest. For the 2012 and 2013 cruises, the shipping of animals was organised by air freight, and animals were stored in plastic bags which contained seawater and pure oxygen, and further sealed. Shrimp were transported in groups of 20-25 while the crabs travelled individually. The bags were stored in boxes loaded with newspaper and ice. The journey back implied a transit through Lisbon, where the bags were reconditioned again for oxygen supply. For the 2013 samples, the journey from the ship to the Océanopolis aquarium lasted about 24 hours, whereas it took 4 days for the 2012 samples, due to logistical problems encountered in Lisbon.

\subsection{Maintenance of vent fauna at the Océanopolis aquarium}

At Océanopolis, shrimp from the 2011 cruise were stored in three large tanks (approximately $100 \mathrm{l} \mathrm{each)} \mathrm{with} \mathrm{aeration,} \mathrm{at} 10^{\circ} \mathrm{C}$, and at atmospheric pressure, while crabs were maintained in smaller (approximately 201 ) tanks at atmospheric pressure, or in the IPOCAMP pressure vessel at in situ pressure (18 MPa). Because crabs did not feed when maintained at atmospheric pressure, it was decided to maintain all of them at in situ pressure, including future arrivals (2012 and 2013). Inside the IPOCAMP, crabs were physically separated in individual perforated PET boxes, in order to avoid fighting confrontations. As soon as the exhibition pressure vessels (two AbyssBoxes) were available (February 2012), 10 
to 20 shrimp and 3 to 5 crabs were placed at in situ pressure $(18 \mathrm{MPa})$ and $10^{\circ} \mathrm{C}$ temperature with permanent flow-through of aerated seawater (see description of AbyssBox aquarium). Re-pressurization of the animals was achieved in a few minutes.

Upon arrival of animals of the 2012 cruise, a dedicated maintenance room was prepared for shrimp at Océanopolis, in order to increase the number of rearing tanks, so that shrimp from different arrivals were not mixed. This allowed their maintenance at a constant $10^{\circ} \mathrm{C}$ temperature and total darkness. For mortality counts and feeding, lights were switched on only a few minutes per day. Standard ambient illumination was then used. All the tanks were run from a unique batch of seawater, where mechanical and biological filtration took place, and the overflow of each tank returned to the batch. The whole unit worked as a semiopen system with a constant natural seawater supply of 5\% of the net volume per hour. In each tank, a $25 \mathrm{~W}$ heater wrapped in PVC foam was placed near the surface (close to the overflow exit), in order to provide a "hotspot" in the $13-28^{\circ} \mathrm{C}$ range, while not being powerful enough to heat the rest of the tank. Temperature was checked daily by the Océanopolis staff, and chemical parameters were measured on a weekly basis. Due to the regular renewal of seawater, these parameters remained very stable (oxygen $=6.5$ to 8.5 $\mathrm{mg} / \mathrm{l}$, nitrates $=1$ to $4 \mathrm{mg} / \mathrm{l}$, nitrites and ammonia $\approx 0$, i.e. below detection threshold) Feeding of all animals was achieved every 4 to 5 days, and several types of food were tested (i.e., blue mussel Mytilus edulis, green crab Carcinus maenas, velvet crab Necora puber), including vent mussels (Bathymodiolus azoricus) which had been frozen after sampling during the 2011 cruise. From the end of 2012, the main food source was Liptoaqua food pellets (Liptosa, Madrid, Spain). Crabs inside IPOCAMP were decompressed a few minutes for feeding, while animals in AbyssBoxes were fed without decompression (see description of AbyssBox). 


\section{Results}

\subsection{The exhibition}

The exhibition was opened to the public on April 7, 2012. Only shrimp and crabs maintained inside AbyssBoxes were exposed (Figure 2), while shrimp maintained at atmospheric pressure were not shown to the public. These were kept as back-ups for the exhibition and also for scientific purposes. The pressure aquaria (AbyssBoxes) were exposed behind a large transparent acrylic wall (Figure 2B), as opposed to just showing the captive animals, behind the main viewport (Figures 2C and D). Reproductions of specific parts of the system, such as the main viewport, or the main assembly screws, were also exposed (not shown) with illustrations of the mechanical constraints imposed to them.

\subsection{Operation of the AbyssBox}

The general water circuit surrounding the AbyssBox is inspired from existing instruments; therefore, operations such as increasing or decreasing pressure, setting flowrates, and opening/closing the vessels, were done according to previous experience, and Océanopolis staff were instructed accordingly. Isobaric feeding (Figure 1), which was an innovative procedure (in reference to existing instruments), proved to be a simple and reliable operation. An important point, while feeding occurred, was to check visually that food would sink towards the AbyssBox when the corresponding valve would be opened (V6, see Figure 1). Because the ambient temperature in the exhibition area was about $19^{\circ} \mathrm{C}$, while that of AbyssBox was $10^{\circ} \mathrm{C}$, condensation occurred on the metallic parts of the pressure vessel, but not on the main acrylic viewport. Condensation water gradually accumulated in large basins stored below the AbyssBox. Due to organic wastes produced by the animals, and occasionally by food that had not been eaten, the inline filter at the outlet of AbyssBox was checked and cleaned every 2 months. The back-pressure valve (see Figure 1) is a crucial item, 
since it sets the working pressure inside the AbyssBox, while functioning in "flow-through" mode. Therefore, this part was checked and cleaned about once a month, to eliminate particles that had passed beyond the inline filter. To allow observations by the public, illumination was provided during day time (11 hours), and switched off at night.

\subsection{Early modifications due to corrosion issues}

During the first weeks of operation, orange-coloured stains appeared inside the AbyssBoxes, localised at interfaces between different parts (connectors, viewport casing, etc.), and also in other parts of the system (back-pressure valve, pump valves, etc.). Corrosion of the stainless steel (pitting) was occurring. Two modifications were then undertaken to solve the problem. One was to include a $\mathrm{Zn}$ corrosion anode which was placed downstream of the AbyssBoxes, between the V2 valve and the filter (Figure 1). Positioning the anode downstream insured that $\mathrm{Zn}$ oxides would not diffuse inside the aquarium. The other decision was to coat the inside of the AbyssBoxes with a $90 \square$ m thick layer of PTFE (polytetrafluoroethylene).

Because the AbyssBoxes had to be sent away for such an operation, the coating was done on one aquarium at a time, while always keeping one AbyssBox functioning for the exhibition.

\subsection{Survival of the animals}

Table 1 provides the initial catch numbers for both crabs and shrimp. Both species are fairly easy to sample once they have been located in situ. Higher catch numbers for $M$.

fortunata shrimp are explained by their greater abundance relative to $S$. mesatlantica crabs, at the Lucky Strike vent field (Desbruyères et al., 2001).

Important mortalities occurred during the first days following sampling and transit back to Océanopolis aquarium. Because animals were gradually sampled at different dives 
throughout the cruises and were difficult to store separately during that time, post-sampling mortalities could only be reliably observed at the end of all sampling events of a given cruise (see Figure 4 for shrimp mortalities). For the 2011 cruise, an 8-day ship transit to Océanopolis followed the end of the cruise, and about $62 \%$ shrimp survival was observed. For the next two cruises, an air-shipping method was used; however, in one case (2012), the survival was $26 \%$ after a 3-day delay in Lisbon, whereas in the other case (2013), the survival was $95 \%$ after a 1-day transit.

Following arrival at Océanopolis aquarium, important shrimp mortalities continued to occur, and after 10 days, survival rates reached about 35\% (190 individuals), 7\% (47 individuals), and 47\% (313 individuals) for 2011, 2012, and 2013 samplings, respectively (Figure 4). Subsequently, mortalities diminished, and after 80 days, the survival rates were about 27\% (147 individuals), 6\% (39 individuals), and 37\% (247 individuals) for the 2011, 2012, and 2013 samplings respectively.

Crab survival seemed to follow a similar trend as shrimp survival, with at least $50 \%$ mortality occurring in the first 10 days, and later stabilizing. However, smaller numbers of individuals (Table 1) precluded precise survival trends. Moreover, inter-individual confrontations for the 2011 sample led to the death of several individuals inside the IPOCAMP pressure vessel, before the animals were physically separated. Still, such a separation was not possible inside the AbyssBoxes; therefore, mortality due to confrontation occasionally continued to occur. Finally, when expressed as a percentage, long-term survival (at August 1, 2014) compared fairly well between shrimp and crabs (Table 1). 


\subsection{Observations of the captive animals}

In addition to the observations made by the Océanopolis staff, a 6-month survey was conducted during winter 2013 to study the behaviour of the two species at in situ pressure (AbyssBox) and the shrimp at atmospheric pressure. The results of this study are presented in Matabos et al. (this issue). The shrimp appeared to be more active in the AbyssBox than at atmospheric pressure. In the AbyssBox and at atmospheric pressure, shrimp were often seen aggregating on the PVC foam (the "hotspot"), while others were dispatched in the aquaria. Crawling and swimming activities were both observed, and the animals reacted to feeding (by gathering on food) within a few minutes at the most (Matabos et al., this issue). Moulting events seemed to occur frequently, as witnessed by the presence of shrimp exuviae at the bottom of the tanks. Exuviae were left in the tanks, and were systematically eaten by the shrimp. Dead shrimp were also fed upon, before they were noticed and removed from the tanks. Some shrimp were gravid when initially sampled, and others showed signs of gonad development during their stay at Océanopolis, reaching in some cases a gravid state, both at atmospheric and in situ pressure. Some of them eventually lost their eggs, and it was not possible to determine if egg hatching had occurred, or if eggs had been lost. However, egg hatching occurred at least once at atmospheric pressure, since one larva (zoea stage) was detected and isolated. Unfortunately, this larva died a few hours after being sampled and isolated (not shown), probably due to a malformation seen on its tail which was curiously bent. This malformation probably caused swimming/displacement problems.

As mentioned in section 2.4. above, and despite being exposed to various foods (vent mussels, blue mussels, green crab, velvet crab, food pellets, ..), crabs fed very little when kept at atmospheric pressure, as compared to being maintained at in situ pressure in AbyssBox or IPOCAMP. For this reason, they were kept at in situ pressure whenever possible. Individuals of different sizes tended to fight, even causing mortality. For this reason, 
only 4 to 5 small crabs were maintained in the AbyssBoxes while the others, kept aside for the exhibition in the IPOCAMP, were separated in individual boxes in order to avoid confrontations. Inside AbyssBoxes, the crabs were generally less mobile than shrimp, remaining for long periods in the same position. They also seemed less attracted than shrimp with respect to the hotspot (the ring-shaped tube embedded in PVC foam). Nevertheless, when the food was inserted, the crabs dominated the feeding area while shrimp settled away, feeding on the remainings (Matabos et al., this issue). Finally, crabs never moulted during their captivity.

\section{Discussion}

\subsection{The choice of species}

Because knowledge was scarce on long-term rearing of deep-sea fauna, and because new pressure vessels had to be specifically designed for such a purpose, an early focus of the project was on species that would be fairly resistant to collection trauma, and to prolonged exposure at atmospheric pressure, while originating from significant ocean depths (>1500 m). Moreover, it was important that the chosen species were sampled in significant numbers, and throughout several cruises, to secure the exhibition and also the scientific study of the animals. Accordingly, the hydrothermal vent crab Segonzacia mesatlantica and shrimp Mirocaris fortunata from the Mid-Atlantic Ridge (MAR) were chosen. An on-going scientific observatory on the Lucky Strike (LS) vent field (EMSO-Açores observatory, Cannat et al., 2011) insured that several cruises would return to this site on a yearly basis (Momarsat cruises, 2010-2014).

The LS vent field lies between 1700 and $1800 \mathrm{~m}$ depth, and hosts a variety of vent endemic species (Desbruyères et al., 2001, 2006). From previous experience of physiological work on vent crabs (Mickel and Childress, 1982; Airriess and Childress, 1994; Martinez et al., 2001; Toullec et al., 2002), and MAR vent crabs in particular (Chausson et al., 2004a, 
2004b), it appeared that some deep bythograeid crabs could survive a few hours or days at atmospheric pressure, provided they were maintained at temperatures of $10^{\circ} \mathrm{C}$ or less. For Mirocaris fortunata, Shillito et al. (2006) found that maintenance at atmospheric pressure was enhanced by low temperatures, and that depth of origin also mattered: at $10^{\circ} \mathrm{C}, 30 \%$ mortality was reached in 9 days, for samples from the shallow Menez Gwen site (ca. 800 m). The same percentage was obtained in one day when shrimp originated from the deeper Rainbow site (2300 m). The choice of Mirocaris fortunata was also re-inforced by the fact that other workers had already succeeded in maintaining this species over a year in their laboratory (Smith et al., 2013).

\subsection{Survival of vent fauna in captivity}

Before arrival at the Océanopolis aquarium, great differences in survival were observed during the transit from the Azores back to France. The 2012 and 2013 transits (26\% vs. $95 \%$ survival rates) were done via air-shipping by the same company, employing similar conditioning of the animals. It seems that either the closer contact of the animals with the ice packing or the longer travel time was responsible for the increase in mortality in 2012. Surprisingly though, the return travel in 2011 lasted longer than in 2012, but with much higher survival rates (62\% vs. $26 \%)$. In this case however, the animals were not manipulated at the end of the cruise, but remained in their tanks in the cold room during their ship transit to France. This suggests that best survival results are obtained by reducing the number of manipulations and by keeping the same maintenance conditions all the way to their final destination.

In all cases, after arrival of the animals at Océanopolis aquarium, mortalities had dropped sharply after about 10 days, suggesting that the remaining individuals had started to acclimate with respect to their maintenance conditions. Whether this acclimation time 
depended on the nature of the species or on its depth of occurrence was not determined. For short-term maintenance of M. fortunata at atmospheric pressure (a few hours, Shillito et al., 2006), mortality rates depended on the depth of origin. Future attempts to sample $M$. fortunata shrimp from a shallower site (Menez Gwen, $800 \mathrm{~m}$ ) would confirm this observation over a longer rearing period.

Our data show that some shrimp lived more than 3 years in captivity, while the longest time for crabs thus far is a little less than 2 years (Table 1). These lifespans are in the range observed for such crustaceans (1-15 years for Caridea, 1-25 years for Brachyoura, review in Vogt, 2012). To what extent these values compare to lifespans of wild animals remains unknown. On the one hand, laboratory data may be considered the result of a protected life under optimal conditions, therefore leading to an overestimation of lifespan in the wild. While this position may be supported by species for which rearing conditions are well known, it is likely not the case here. Our maintenance conditions certainly need to be improved through greater knowledge and a longer experience. For example, the fact that the crabs were never observed moulting suggests that rearing conditions are not optimal. Alternatively, the crabs in our study may have already reached a terminal moult before capture, as observed for some crabs (Vogt, 2012). However, other workers have managed to maintain vent crab species from shallower habitats (e.g., Austinograea yunohana, from approximately $500 \mathrm{~m}$ depth) for more than 6 years in captivity (Tsuchida et al., 1998), while also observing moulting of the captive specimens. Miyake et al. (2007) improved survival of these crabs by chemically simulating the presence of vent fluid. Finally, the crabs in our study only fed when maintained at in situ pressure (inside AbyssBox or IPOCAMP), unlike shrimp with a feeding behaviour not impaired by prolonged exposure to atmospheric pressure. The reason for this difference in behaviour is unclear; however, the fact that shallower vent crab species have been successfully maintained at atmospheric pressure by other workers 
(Tsuchida et al., 1998, Miyake et al. 2007) suggests that for crabs at least, an important depth of origin (1700 $\mathrm{m}$ in our study) may be a limitation for long-term rearing at atmospheric pressure.

\subsection{Future Research}

The presence of a facility such as Océanopolis is a real plus for marine biologists since it not only provides the infrastructure, maintenance, and staff 7 days a week, but also 20-years of expertise in maintaining marine animals alive under optimal conditions. The maintenance of vent species in captivity for 3 years creates opportunities for study of specific aspects of their development and behaviour, and to test various ecological hypotheses. Future research includes studies of species interactions and behaviour, sensorial adaptations, reproduction, and larval development. Responses and adaptations of vent species to sulphide and heavy metal exposition are also important subjects for future research. Such work would parallel that of the European project MIDAS (2014-2017, Moskvitch, 2014) which aims at exploring the potential impacts of deep-sea mining on marine ecosystems. The experiments done (Matabos et al., this issue) and planned at Océanopolis will complement this type of research in the field, through annual oceanographic cruises and deep-sea observatories (Sarrazin et al., 2014). The facility can serve as a testing bed. Finally, the long-term maintenance of shrimp either at atmospheric or in situ pressure, while fed on the same diet (pellets), raises another interesting area of research, i.e. to test the role of pressure in lipid composition of membranes. This would enable the exploration of homeoviscous adaptations of these animals (Airries and Childress, 1994; New et al., 2014) and possibly investigation of phenotypic plasticity in membrane composition in response to different rearing pressures, as observed for some bacteria (Yayanos, 1995; Wang et al., 2014). 


\subsection{Evolution of the AbyssBox and exhibition}

Ideally, in the longer term, we aim at rearing the species in aquaria and insure the provision of the exhibition and scientific studies without having to sample them in the field. Future challenges include long-term simulation in pressure aquaria of the extreme thermal and chemical conditions encountered by deep vent species. This would benefit from the previous experience of other workers (Holden, 1998, Miyake et al., 2007), and may allow the rearing of species whose subsistence is strongly linked to venting, such as the shrimp Rimicaris exoculata (Williams and Rona, 1986). This would further improve our understanding of their distributions and survival, in their natural habitats. It would also bring scientists closer to the simulation of a complete vent ecosystem, with the presence of vent species and their hard sulphide substrata. It is likely that such perspectives would require the design of larger pressure aquaria, in order to accommodate species of larger size and/or greater numbers of individuals. Technically speaking, aquarium volumes as large as 1001 may be considered, and the limitation for such designs would mainly be a matter of funding. Finally, we are also aiming at rearing other peculiar deep-sea species, including giant siboglinid tubeworms and potentially more fragile species, such as fish or cephalopods. In these cases, isobaric equipment for sampling and transfer would have to be adapted from existing scientific equipment (Shillito et al., 2008, Ravaux et al., 2013).

\section{Acknowledgements}

We wish to thank Jean-Paul Alayse and Eric Hussenot, and our respective institutions, for their early and strong support of this project. We would also like to warmly thank Océanopolis staff members for their important contributions: Yann Le Nozerh, Jean-Marie Carré, Olivier Gouello, Jean Goasdoué, Céline Liret, Anne Rognant, Danielle Quéméneur. We acknowledge the captains and crews of the oceanographic ships Pourquoi Pas? 
(Momarsat 2011 and Biobaz 2013 cruises) and Thalassa (Momarsat 2012 cruise) and the pilots of Victor6000 Remotely Operated Vehicle, for their dedicated assistance during sampling. We are also grateful to Gérard Hamel, François Lallier, Mathilde Cannat, Jérome Blandin, Ana Colaço, Ricardo Santos, and Sven Thatje for scientific advice and support. We finally acknowledge the contribution of "Flying Sharks" (Lisbon, Portugal) for air shipping of the animals, and of the "Institut Français de la Corrosion" (Brest, France), for advice regarding corrosion issues. The project was funded by Océanopolis Brest'Aim S.E.M., and we acknowledge initial financial support of the G.D.R. ECCHIS (Ifremer, CNRS, UPMC).

\section{References}

Airries, C.N., Childress J.J., 1994. Homeoviscous properties implicated by the interactive effects of pressure and temperature on the hydrothermal vent crab Bythograea thermydron. Biol. Bull. 187, 208-214.

Cannat, M., Sarradin, P., Blandin, J., Escartin, J., Colaco, A., 2011. MoMar-Demo at Lucky Strike: a near-real time multidisciplinary observatory of hydrothermal processes and ecosystems at the Mid-Atlantic Ridge. In: AGU Fall Meeting, Abstract OS22A-05, San Francisco.

Chausson, F., Sanglier, S., Leize, E., Hagège, A., Bridges, C.R., Sarradin, P.-M., Shillito, B., Lallier, F.H., Zal, F., 2004a. Respiratory adaptations of a deep-sea hydrothermal vent crab. Micron. 35, 27-29.

Chausson, F., Sanglier, S., Leize, E., Hagège, A., Bridges, C.R., Sarradin, P.-M., Shillito, B., Lallier, F.H., Zal, F., 2004b. Respiratory adaptations to the deep-sea hydrothermal vent environment: the case of Segonzacia mesatlantica, a crab from the Mid-Atlantic Ridge. Micron. 35, 31-41.

Cuvelier, D., Legendre, P., Laes, A., Sarradin, P.-M., Sarrazin, J., 2014. Rythms and community dynamics of a hydrothermal tubeworm assemblage at Main Endeavour Field - a multidisciplinary deep-sea observatory approach. PLoS One 9(5): e96924. doi:10.1371/journal.pone.0096924

Desbruyères, D., Biscoito, M., Caprais, J.-C., Colaço, A., Comtet, T., Crassous, P., Fouquet, Y., Khripounoff, A., Le Bris, N., Olu, K. et al., 2001. Variations in deep-sea hydrothermal vent communities on the Mid-Atlantic Ridge near the Azores plateau. Deep-Sea Res. I Oceanogr. Res. Pap. 48, 1325-1346.

Desbruyères, D., Segonzac, M. and Bright, M., 2006. Handbook of Deep-sea Hydrothermal Vent Fauna. IFREMER (Institut Français de la recherche en Mer), Brest.

Devine, J.A., Baker, K.D., Haedrich, R.L., 2006. Deep-Sea fishes qualify as endangered. 
Nature 439, 29.

Fang, J., Zhang, L., Bazylinski, D. A., 2010. Deep-sea piezosphere and piezophiles: geomicrobiology and biogeochemistry. Trends Microbiol. 18, 413-422, doi:10.1016/j.tim.2010.06.006

Girguis, P.R., Lee, R.W., 2006. Thermal preference and tolerance of Alvinellids. Science 312, 231.

Glover, A.G., Smith, C.R., 2003. The deep-sea floor ecosystem: current status and prospects of anthropogenic change by the year 2025. Env. Conserv. 30, 219-241.

Hamasaki, K., Nakajima, K., Tsuchida, S., Kado, R., Kitada, S., 2010. Number and duration of zoeal stages of the hydrothermal vent crab Gandalfus yunohana from laboratory reared specimens. J. Crust. Biol. 30(2), 236-240.

Holden C., 1998. Farming tubeworms. Science 279, 66.

Juniper, S.K., Escartin, J., Cannat, M., 2007. Monitoring and observatories: multidisciplinary, time-series observations at mid-ocean ridges. Oceanography 20(1), 128-137.

Juniper, S.K., Matabos, M., Miha'1y, S., Ajayamohan, R.S., Gervais, F. et al., 2013. A year in Barkley Canyon: a time-series observatory study of mid-slope benthos and habitat dynamics using the NEPTUNE Canada network. Deep-Sea Res. II Top. Stud. Oceanogr. 92, 114-123.

Koyama S., Miwa, T., Horii, M., Ishikawa, Y., Horikoshi, K., Aizawa, M., 2002. Pressurestat aquarium system designed for capturing and maintaining deep-sea organisms. Deep-Sea Res. I Oceanogr. Res. Pap. 49, 2095-2102.

Koyama, S., Nagahama, T., Ootsu, N., Takayama, T., Horii, M., Konishi, S., Miwa, T., Ishikawa, Y., Aizawa, M., 2005. Survival of Deep-Sea Shrimp (Alvinocaris sp.) During decompression and larval hatching at atmospheric pressure. Mar. Biotech. 7, 272-278.

Martin, J.W., Christiansen, J.C., 1995. A new species of the shrimp genus Chorocaris Martin And Hessler, 1990 (Crustacea, Decapoda, Bresiliidae) from hydrothermal vent fields along the Mid-Atlantic Ridge. Proc. Biol. Soc. Wash. 108(2), 220-227.

Martinez, A.-S., Toullec, J.-Y., Shillito, B., Charmantier-Daures, M., Charmantier, G., 2001. Hydromineral regulation in the hydrothermal vent crab Bythograea thermydron. Biol. Bull. 201, 167-174.

Mengerink, K.J., Van Dover, C.L., Ardron, J., Baker, M., Escobar-Briones, E., Gjerde, K., Koslow, J.A., Ramirez-Llodra, E., Lara-Lopez, A., Squires, D., Sutton, T., Sweetman, A.K., Levin, L.A., 2014. A call for deep-ocean stewardship. Science 344, 696-698.

Mickel, T.J., Childress, J.J., 1982. Effects of pressure and temperature on the EKG and heart rate of the hydrothermal vent crab Bythogrea thermydron (Brachyura). Biol. Bull. 162, 70-82. 
Miyake, H., Kitada, M., Tsuchida, S., Okuyama, Y., Nakamura, K., 2007. Ecological aspects of hydrothermal vent animals in captivity at atmospheric pressure. Mar. Ecol. 28, 86-92.

Moskvitch, K., 2014. Health check for deep-sea mining. Nature 512, 122-123.

New, P., Brown, A., Oliphant, A., Burchell, P., Smith, A., Thatje, S., 2014. The effects of temperature and pressure acclimation on the temperature and pressure tolerance of the shallow-water shrimp Palaemonetes varians. Mar. Biol. 161, 697-709. DOI 10.1007 / s00227 - $013-2371-9$.

Pradillon, F., 2011. High hydrostatic pressure environments. In: Bell, E. (Ed.), Life at Extremes: Environments, Organisms, and Strategies for Survival. CABI, UK, pp 271295.

Ramirez-Llodra, E., Tyler, P.A., Baker, M.C., Bergstad, O.A., Clark, M.R., et al., 2011. Man and the last great wilderness: human impact on the deep sea. PLoS One. 6(7). e22588. doi:10.1317/journal.pone.0022588.

Ravaux, J., Hamel, G., Zbinden, M., Tasiemski, A.A., Boutet, I., Léger, N., Tanguy, A., Jollivet, D., Shillito, B., 2013. Thermal limit for metazoan life in question: in vivo heat tolerance of the Pompeii worm. PLoS One. 8(5). e64074. doi: 10.137/journal.pone.0064074.

Sarrazin, J., Blandin, J., Delauney, L., Dentrecolas, S., Dorval, P., Dupont, J., Legrand, J., et al., 2007. TEMPO: a new ecological module for studying deep-sea community dynamics at hydrothermal vents. In: OCEANS 2007-Europe. Ieee, pp. 1-4.

Sarrazin, J., Cuvelier, D., Peton, L., Legendre, P., Sarradin, P.-M., 2014. High-resolution dynamics of a deep-sea hydrothermal mussel assemblage monitored by the EMSOAçores MoMAR observatory. Deep-Sea Res. I Oceanogr. Res. Pap. 90, 62-75.

Shillito, B., Jollivet, D., Sarradin, P.-M, Rodier, P., Lallier, F., Desbruyères, D., Gaill, F., 2001. Temperature resistance of Hesiolyra bergi, a polychaetous annelid living on vent smoker walls. Mar. Ecol. Prog. Ser. 216, 141-149.

Shillito, B., Le Bris, N., Hourdez, S., Ravaux, J., Cottin, D., Caprais, J.-C., Jollivet, D., Gaill, F., 2006. Temperature resistance studies on the deep-sea vent shrimp Mirocaris fortunata. J. Exp. Biol. 209, 945-955.

Shillito, B., Hamel, G., Duchi, C., Cottin, D., Sarrazin, J., Sarradin, P.-M., Ravaux, J., Gaill, F., 2008. Live capture of megafauna from $2300 \mathrm{~m}$ depth, using a newly-designed pressurised recovery device. Deep-Sea Res. I Oceanogr. Res. Pap. 55, 881-889.

Shillito, B., Gaill, F., Ravaux, J., 2014. The IPOCAMP pressure incubator for deep-sea fauna. J. Mar. Sci. Technol. (Taiwan). 22(1), 97-102. doi: 10.6119/JMST-013-0718-3.

Smith, F., Brown, A., Mestre, N.C., Reed, A.J., Thatje, S., 2013. Thermal adaptations in deep-sea hydrothermal vent and shallow-water shrimp. Deep-Sea Res. II Top. Stud. Oceanogr. 92, 234-239. 
Spicer, J.I., 2014. What can an ecophysiological approach tell us about the physiological responses of marine invertebrates to hypoxia? J. Exp. Biol. 217, 46-56. doi:10.1242/jeb.090365.

Toullec, J.-Y., Vinh, J., Le Caer, J.-P., Shillito, B., Soyez, D., 2002. Structure and Phylogeny of the crustacean hyperglycemic hormone and its precursor from a hydrothermal vent crustacean: the crab Bythograea thermydron. Peptides 23, 31-42.

Tsuruwaka, Y., Shimada, E., 2011. Rearing and spawning of the deep-sea fish Malacocottus gibber in the laboratory. Ichthyol. Res. 58, 188-190.

Tsuchida, S., Fujikura, K., Hashimoto, J., Fujiwara, Y., Hunt, J.C. and Lindsay, D.J., 1998. Molting of bythograeid crabs under laboratory conditions. JAMSTEC Deep-Sea Res. $14,515-520$.

Vogt, G., 2012. Ageing and longevity in the Decapoda (Crustacea): A review. Zool. Anzeiger. 251, 1-25.

Wang, J., Li, J., Dasgupta, S., Zhang, L., Golovko, M.Y., Golovko, S.A., Fang, J., 2014. Alterations in membrane phospholipid fatty acids of gram-positive iezotolerant bacterium Sporosarcina sp. DSK25 in response to growth pressure. Lipids. 49, 347-356. doi 10.1007/s11745-014-3878-7.

Williams, A., Rona, P., 1986. Two new caridean shrimp (Bresiliidae) from a hydrothermal field on the Mid-Atlantic Ridge. J. Crust. Biol. 6(3), 446-462.

Williams, A.B., 1988. New marine decapod crustaceans from waters influenced by hydrothermal discharge, brine, and hydrocarbon seepage. Fish. Bull. 86(2), 263-286.

Yayanos, A., 1978. Recovery and maintenance of live amphipods at a pressure of 580 bars from an ocean depth of 5700 meters. Science 200, 1056-1059.

Yayanos, A., 1995. Microbiology to 10500 meters in the dseep ea. Ann. Rev. Microbiol. 49, 777-805. 


\section{Figure captions}

Figure 1. Schematic representation of the AbyssBox.Arrows represent circulation of the seawater originating from the high pressure pump (HP), tothe back-pressure valve (BP). Outside feeding events, the seawater circulates from HP to BP, through AbyssBox, with valves V1 and V2 opened (all other valves are closed). A heating pump (HW) circulates heated fluid $\left(30^{\circ} \mathrm{C}\right)$ inside a tubular ring, thereby providing a hotspot for captive animals. F: inline $1 \mathrm{~mm}$ mesh filter, cl: closing lid at rear of AbyssBox, vp: main conical-shaped viewport, at the front of the AbyssBox.

To provide food in an isobaric way, food is introduced through valve V5, before closing the latter. This is followed by opening V3, closing V1 and V2, opening V4, and finally V6 for introduction of food by gravity.

Figure 2. The public exhibition.

A: Rear view of the AbyssBox. cl : closing lid (see also Figure 1), which allows initial introduction of animals inside the aquarium.

B: Front view of the 2 AbyssBoxes, as proposed to the public. $r$ : LCD readings displaying pressure and temperature values inside the AbyssBox. vp : main viewport.

C: Segonzacia mesatlantica crabs and Mirocaris fortunata shrimp resting on the foam. Four crabs are on the upper part of the photograph, in the background. Shrimp are in the lower part of the photograph, and aggregate close to the ring-shaped tube (see also D).

$\mathrm{D}$ : Closer view of the main viewport, which is $15 \mathrm{~cm}$ in diameter. A ring-shaped tube (rt) is circulated with warm fluid. Therefore, the PVC foam (pf) wrapped around this tube provides a warm substrata, creating a hotspot in the aquarium. 
Figure 3: The animals.

A: The musselbed assemblage (Bathymodiolus azoricus) habitat of Mirocaris fortunata (shrimp), and Segonzacia mesatlantica (crabs).

B: Mirocaris fortunata specimen. Total length of the animal is about 2-3 cm.

C: Segonzacia mesatlantica specimen. The cephalothorax width of these animals is about 2-5 cm.

Figure 4. Survival of shrimp (in \%) at atmospheric pressure, as a function of the number of days before or after arrival at the Océanopolis aquarium. 100\% survival corresponds to the day the ship ended its cruise and reached Faïal harbour (initial catch), and day 0 corresponds to the arrival at Océanopolis aquarium. Circles, squares and triangles correspond to 2011, 2012, and 2013 cruises, respectively.

Table 1. Number of live individuals for both captured species, crabs (S. mesatlantica) and shrimp (M. fortunata), at the end of each cruise, and on August 1, 2014.

The last line of each set gives the lifespan observed in captivity. Crabs of the 2011 cruise had all died by July 3, 2013. Numbers in parentheses represent percentages of the initial catch. 


\section{Figure captions}

Figure 1. Schematic representation of the AbyssBox.Arrows represent circulation of the seawater originating from the high pressure pump (HP), tothe back-pressure valve (BP). Outside feeding events, the seawater circulates from HP to BP, through AbyssBox, with valves V1 and V2 opened (all other valves are closed). A heating pump (HW) circulates heated fluid $\left(30^{\circ} \mathrm{C}\right)$ inside a tubular ring, thereby providing a hotspot for captive animals. F: inline $1 \mathrm{~mm}$ mesh filter, cl: closing lid at rear of AbyssBox, vp: main conical-shaped viewport, at the front of the AbyssBox.

To provide food in an isobaric way, food is introduced through valve V5, before closing the latter. This is followed by opening V3, closing V1 and V2, opening V4, and finally V6 for introduction of food by gravity.

Figure 2. The public exhibition.

A: Rear view of the AbyssBox. $\mathrm{cl}$ : closing lid (see also Figure 1), which allows initial introduction of animals inside the aquarium.

B: Front view of the 2 AbyssBoxes, as proposed to the public. $r$ : LCD readings displaying pressure and temperature values inside the AbyssBox. vp : main viewport.

C: Segonzacia mesatlantica crabs and Mirocaris fortunata shrimp resting on the foam. Four crabs are on the upper part of the photograph, in the background. Shrimp are in the lower part of the photograph, and aggregate close to the ring-shaped tube (see also D).

$\mathrm{D}$ : Closer view of the main viewport, which is $15 \mathrm{~cm}$ in diameter. A ring-shaped tube (rt) is circulated with warm fluid. Therefore, the PVC foam (pf) wrapped around this tube provides a warm substrata, creating a hotspot in the aquarium. 
Figure 3: The animals.

675

676
A: The musselbed assemblage (Bathymodiolus azoricus) habitat of Mirocaris fortunata (shrimp), and Segonzacia mesatlantica (crabs).

B: Mirocaris fortunata specimen. Total length of the animal is about $2-3 \mathrm{~cm}$.

C: Segonzacia mesatlantica specimen. The cephalothorax width of these animals is about 2-5 $\mathrm{cm}$.

Figure 4. Survival of shrimp (in \%) at atmospheric pressure, as a function of the number of days before or after arrival at the Océanopolis aquarium. 100\% survival corresponds to the day the ship ended its cruise and reached Faïal harbour (initial catch), and day 0 corresponds to the arrival at Océanopolis aquarium. Circles, squares and triangles correspond to 2011, 2012, and 2013 cruises, respectively.

Table 1. Number of live individuals for both captured species, crabs (S. mesatlantica) and shrimp (M. fortunata), at the end of each cruise, and on August 1, 2014.

The last line of each set gives the lifespan observed in captivity. Crabs of the 2011 cruise had all died by July 3, 2013. Numbers in parentheses represent percentages of the initial catch. 
Figure 1

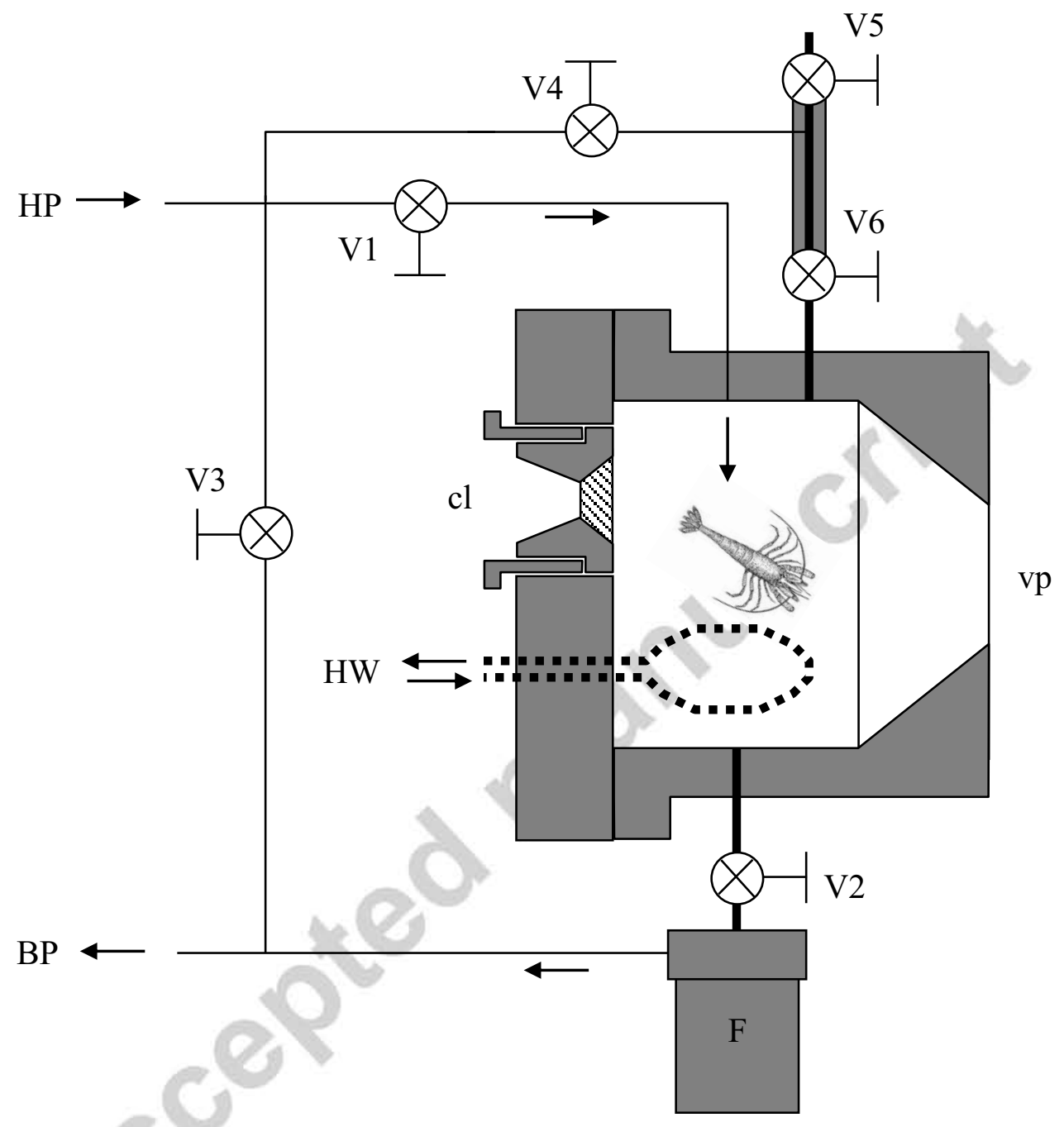


Figure 2
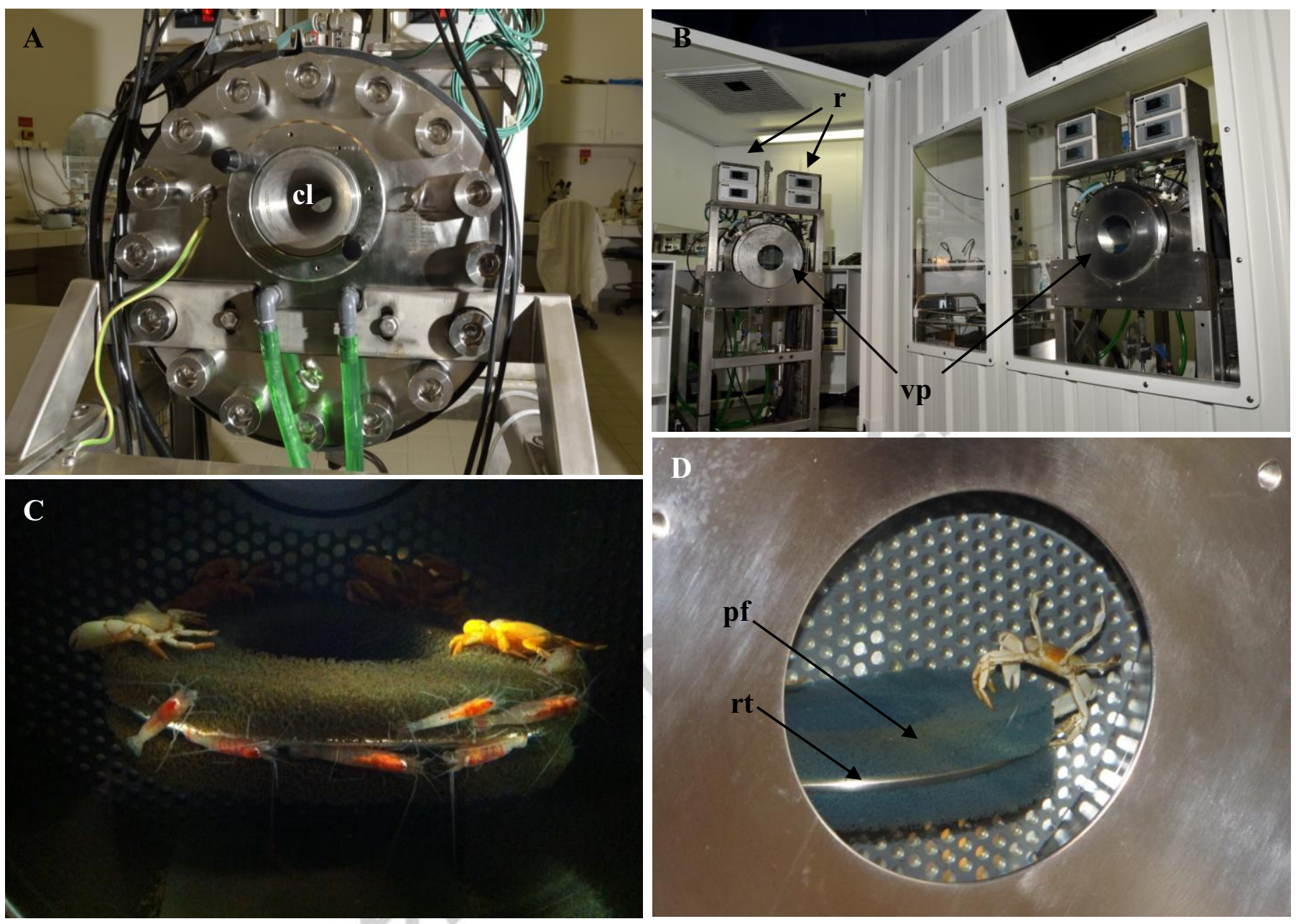
Figure 2 black and white
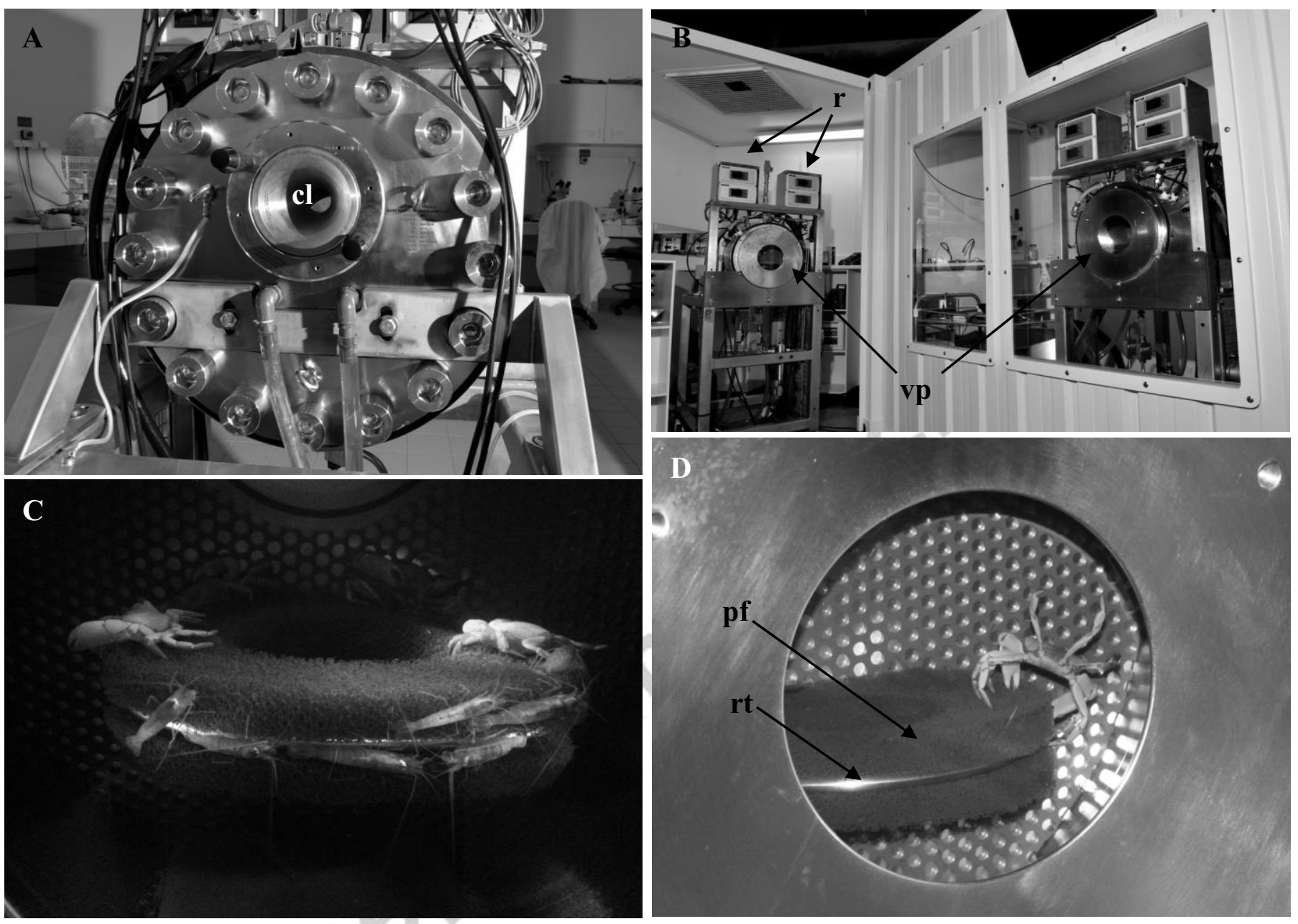
Figure 3

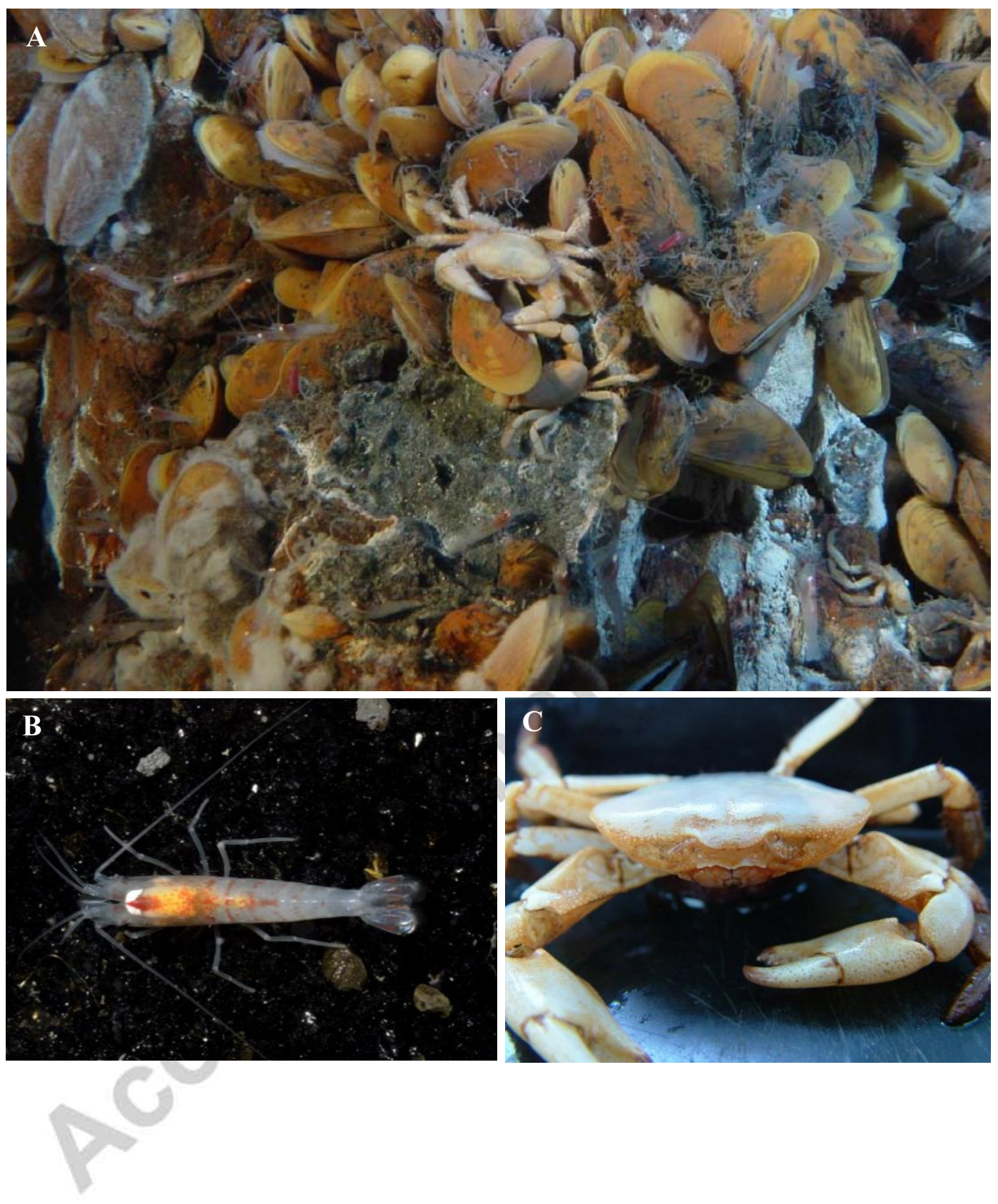


Figure 3 black and white

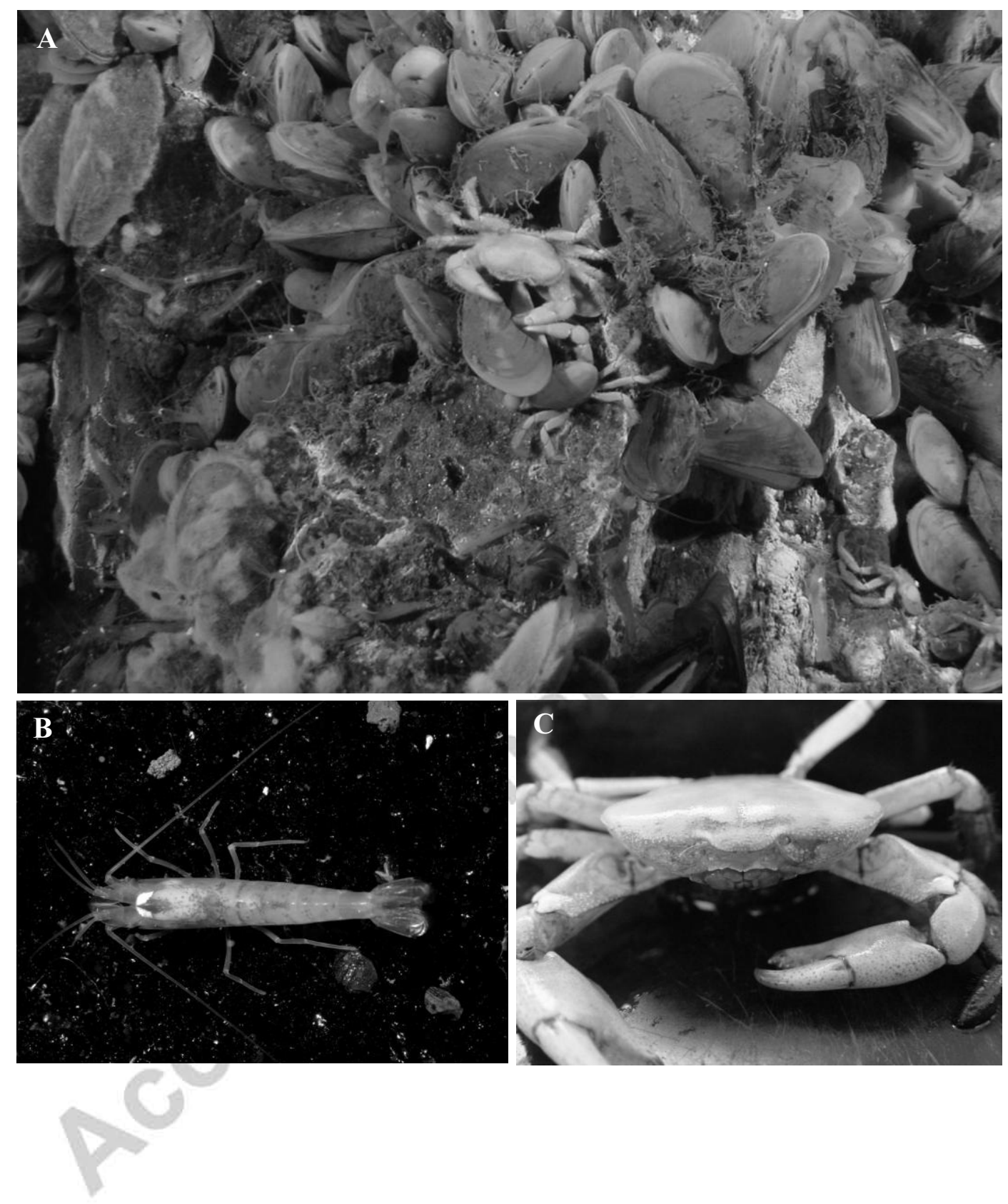


Figure 4

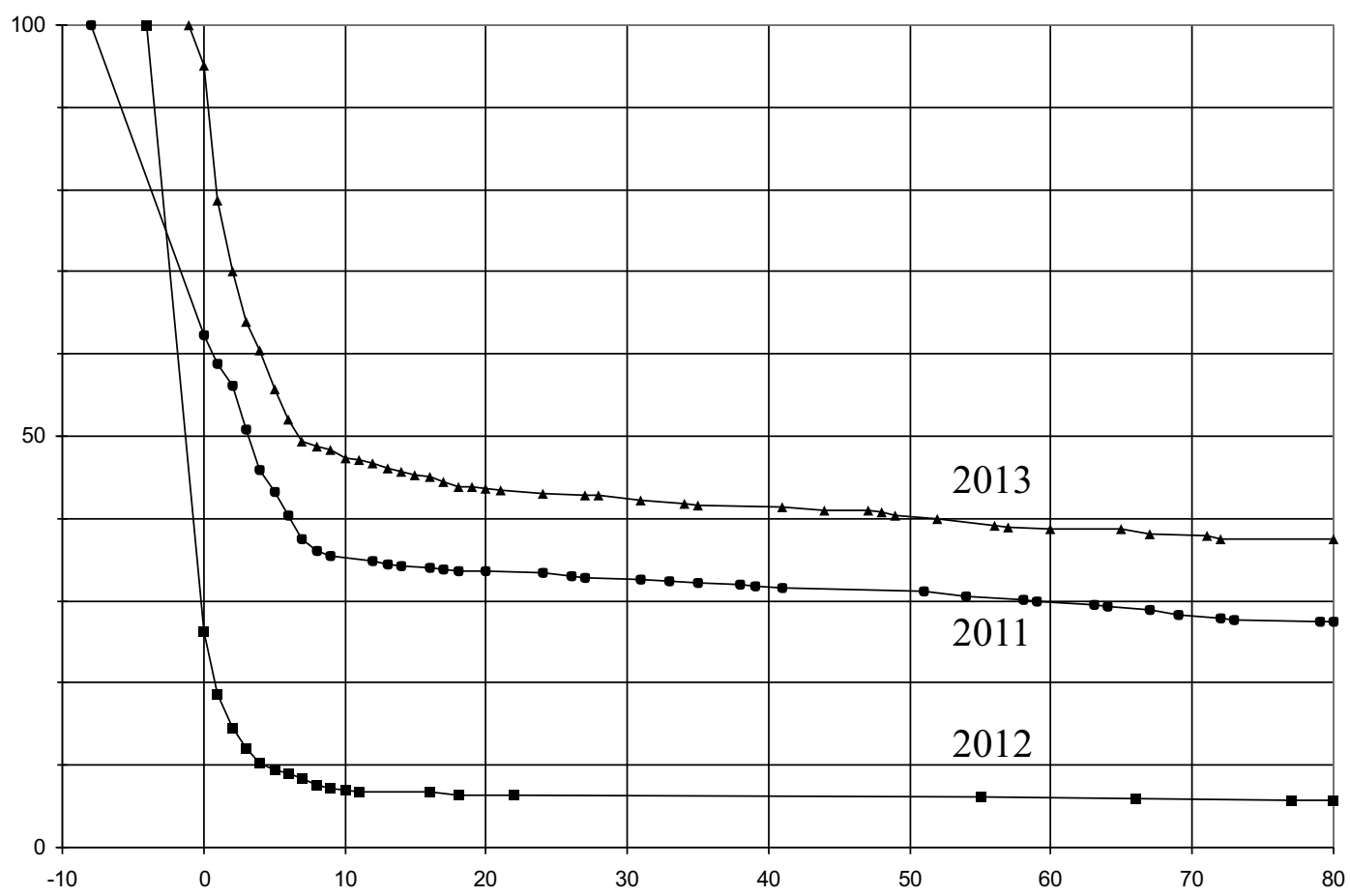


Figure 1 TIF

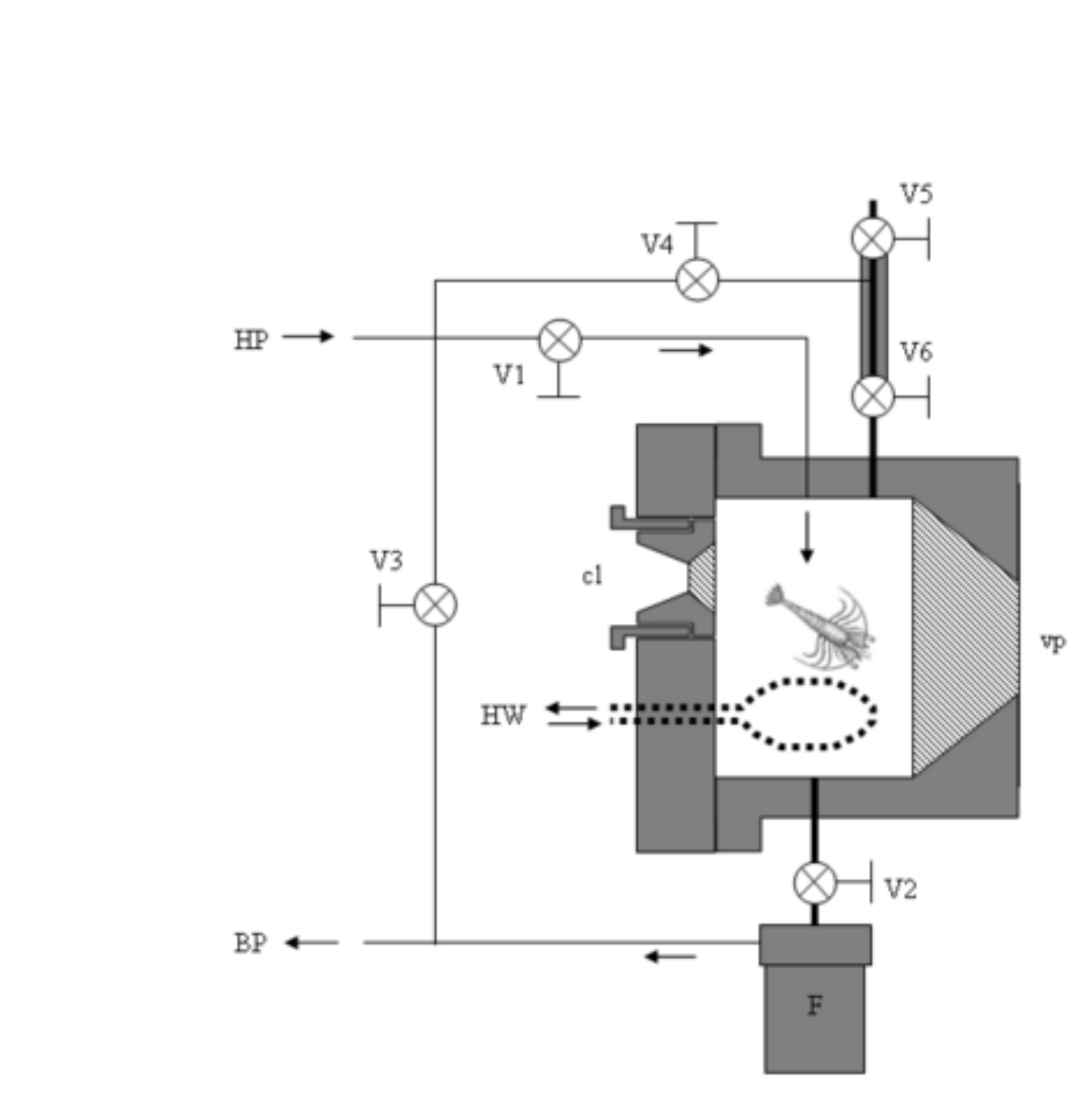

p

\section{Figure 1 TIF}

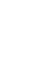

政
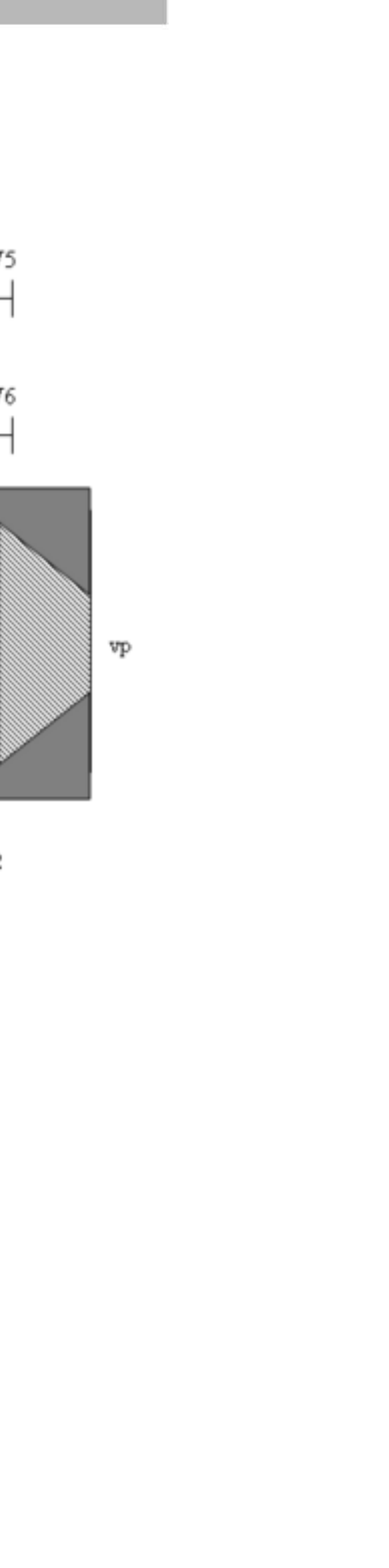

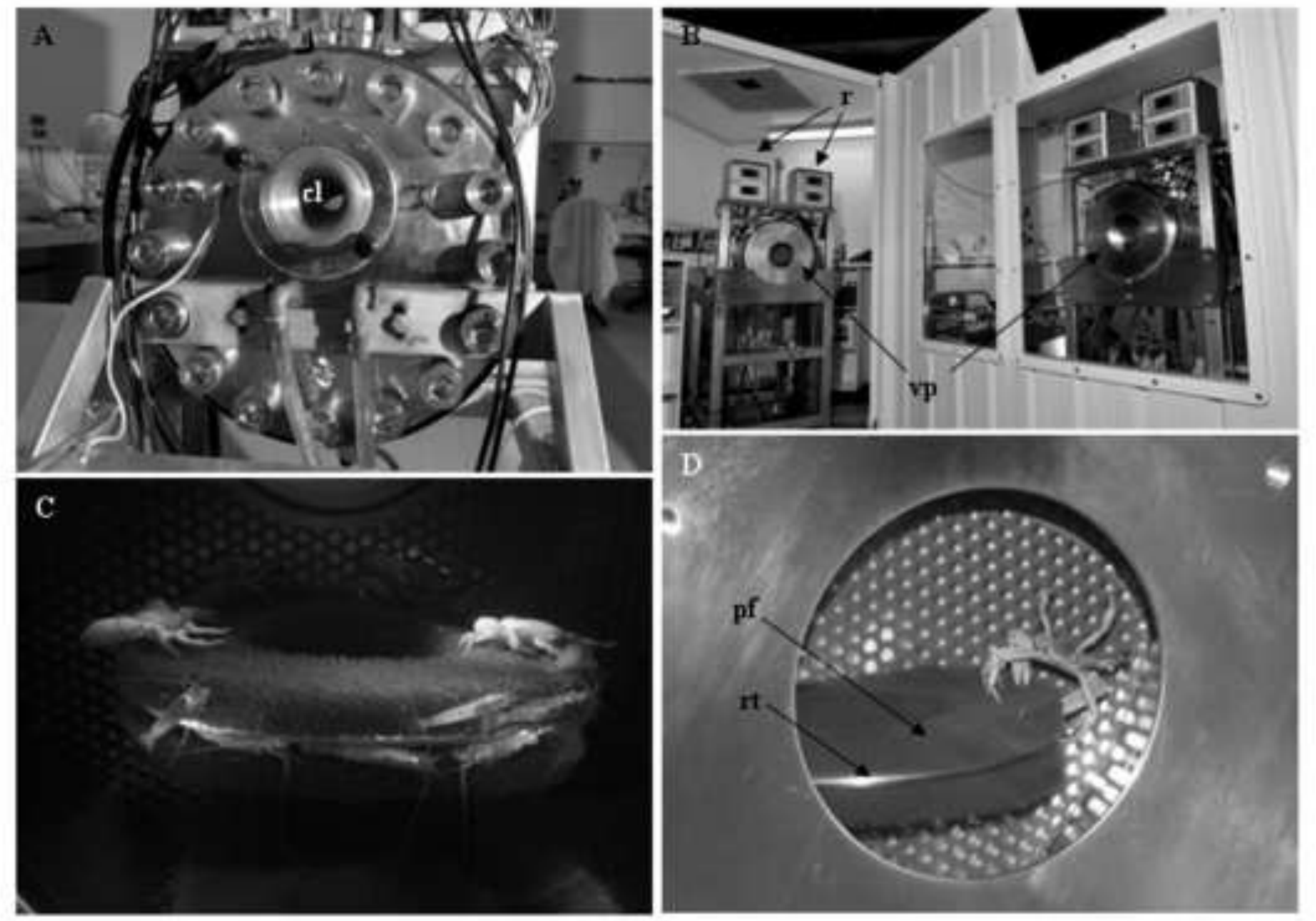
Table 1

\begin{tabular}{|l|c|c|c|}
\hline Segonzacia mesatlantica & $\mathbf{2 0 1 1}$ & $\mathbf{2 0 1 2}$ & $\mathbf{2 0 1 3}$ \\
\hline Initial catch & 14 & 19 & 8 \\
\hline Alive on August 1st, 2014 (\%) & $0(0)$ & $1(5.3)$ & $3(37.5)$ \\
\hline Number of days in captivity & 705 & 731 & 343 \\
\hline
\end{tabular}

\begin{tabular}{|l|c|c|c|}
\hline Mirocaris fortunata & $\mathbf{2 0 1 1}$ & $\mathbf{2 0 1 2}$ & $\mathbf{2 0 1 3}$ \\
\hline Initial catch & 537 & 669 & 660 \\
\hline Alive on August 1st, 2014 (\%) & $14(2.6)$ & $16(2.4)$ & $215(32.6)$ \\
\hline Number of days in captivity & 1097 & 731 & 343 \\
\hline
\end{tabular}




\begin{tabular}{|l|c|c|c|}
\hline Segonzacia mesatiantica & $\mathbf{2 0 1 1}$ & $\mathbf{2 0 1 2}$ & $\mathbf{2 0 1 3}$ \\
\hline Initial catch & 14 & 19 & 8 \\
\hline Alive on August 1st, 2014 (\%) & $0(0)$ & $1(5.3)$ & $3(37.5)$ \\
\hline Number of days in captivity & 705 & 731 & 3.43 \\
\hline
\end{tabular}

\begin{tabular}{|l|c|c|c|}
\hline Mirocaris fortunata & $\mathbf{2 0 1 1}$ & $\mathbf{2 0 1 2}$ & $\mathbf{2 0 1 3}$ \\
\hline Initial catch & 537 & 669 & 660 \\
\hline Alive on August 1st, 2014 (\%) & $14(2.6)$ & $16(2.4)$ & $215(32.6)$ \\
\hline Number of days in captivity & 1097 & 731 & 343 \\
\hline
\end{tabular}

